\title{
Participation and performance trends in 6-hour ultra-marathoners - a retrospective data analysis of worldwide participation from 1991-2010
}

\author{
LUCA EHRENSPERGER ${ }^{1}$, BEAT KNECHTLE ${ }^{1,2}$, CHRISTOPH ALEXANDER RÜST ${ }^{1}$, THOMAS $^{2}$ \\ ROSEMANN ${ }^{1}$ \\ ${ }^{1}$ Institute of General Practice and for Health Services Research, University of Zurich, Zurich, Switzerland \\ ${ }^{2}$ Gesundheitszentrum St. Gallen, St. Gallen, Switzerland
}

\begin{abstract}
Ehrensperger, L., Knechtle, B., Rüst, C.A. \& Rosemann, T. (2013). Participation and performance trends in 6-hour ultra-marathoners - a retrospective data analysis of worldwide participation from 1991-2010. J. Hum. Sport Exerc., 8(4), pp.905-924. Participation trends in 6-hour ultra-marathons held word-wide were investigated to gain basic demographic data on 6-hour ultra-marathoners and where these races took place. Participation trends and the association between nationality and race performance were investigated in all 6-hour races held worldwide between 1991 and 2010. Participation increased linearly in both women and men across years. The annual number of finishes was significantly higher in men than in women $(P=0.013)$. The male-to-female ratio remained stable at $\sim 4$ since 1991. Runners in age group $45-49$ years showed the largest increase in participation for both men (800 participants in 18 years) and women (208 participants in 16 years). Europe attracted most of the runners from other continents (166 runners), more than all other continents combined (55 runners). European runners also showed the best top ten performances $(73 \pm 3 \mathrm{~km}$ for women and $77 \pm 11 \mathrm{~km}$ for men), while African (with $65 \pm 9 \mathrm{~km}$ for men) and South American ( $54 \pm 4 \mathrm{~km}$ for women and $65 \pm 2 \mathrm{~km}$ for men) runners showed the weakest. To summarize, participation in 6-hour ultra-marathons increased across years. Most of the development took place in Europe and in athletes in the age group 45-49 years. Europe also attracted the most diverse field of athletes with runners from all other continents. European runners accounted for the most runners and achieved the best top ten performances. Key words: ULTRA-ENDURANCE, RUNNING, NATIONALITY, AGE, GENDER.
\end{abstract}

\footnotetext{
Corresponding author. Facharzt FMH für Allgemeinmedizin, Gesundheitszentrum St. Gallen, Vadianstrasse 26, $9001 \mathrm{St}$. Gallen, Switzerland

E-mail: beat.knechtle@hispeed.ch

Submitted for publication March 2013

Accepted for publication November 2013

JOURNAL OF HUMAN SPORT \& EXERCISE ISSN 1988-5202

(c) Faculty of Education. University of Alicante

doi:10.4100/jhse.2013.84.03
} 


\section{INTRODUCTION}

Six-hours ultra-running describes a kind of ultra-running competition where runners have six hours in time to complete as many kilometres as possible. Strictly speaking, these 6-hour ultra-marathons do not comply with the definition of an ultra-endurance sport, defined as an endurance sport exceeding 6 hours in duration (Zaryski \& Smith, 2005). In comparison to shorter running races such as a marathon, long-term preparation (Zaryski \& Smith, 2005), personal nutrition (Rapoport, 2010), environmental stress management (Parise \& Hoffman, 2011) and psychological toughness (Zaryski \& Smith, 2005) become the central aspects of training to improve performance in such ultra-endurance competitions (Zaryski \& Smith, 2005).

The relationship between variables of physiology (Lazzer et al., 2011, Millet et al., 2011), cognition (Parry et al., 2011), anthropometry (Knechtle et al., 2010a, 2010b, 2012), training (Knechtle et al., 2010a, 2010b, 2012), pre-race experience (Knechtle et al., 2010a, 2010b, 2011), gender (Lepers \& Maffiuletti, 2011) and age (Knechtle et al., 2012) with performance in ultra-endurance running competitions have been investigated. In 24-hours treadmill ultra-marathon performance, maximum oxygen uptake (VO2max) and the ability to run at a high \%VO2max over time seemed to be the main physiological parameters correlated with better performance (Millet et al., 2011). Furthermore, it appeared that anthropometric characteristics such as body mass (Knechtle et al., 2010a, 2010b), body height (Knechtle et al., 2010a), body mass index (Knechtle et al., 2010a, 2010b), percent body fat (Knechtle et al., 2010a, 2010b), circumferences of limbs (Knechtle et al., 2010a, 2010b) and thicknesses of skin-folds (Knechtle et al., 2010a) showed no correlation with race performance in ultra-endurance competitions, while previous experience (Knechtle et al., 2011b, Herbst et al., 2011), training and especially training intensity (Knechtle et al., 2010a, 2010b) on the other hand highly correlated with race performance.

However, ethnicity and nationality also greatly influenced long-distance running performance. East African runners, in particular Kenyan (Baker \& Horton, 2003, Larsen, 2003, Onywera et al., 2006), Ethiopian (Scott et al., 2003) and Eritrean (Lucia et al., 2006) runners have been dominating long-distance running events, especially marathon races, for several years. These findings underline the importance of good knowledge on basic demographic information of runners in analysing their running performances.

Regardless of the athlete's nationality, age (Knechtle et al., 2012) and gender (Lepers \& Maffiuletti, 2011) can also greatly influence ultra-running performance. Ultra-endurance running gained popularity most of all amongst older athletes, where runners over 40 years of age accounted for less than $40 \%$ in 1980 and then gained to account for 65 to $70 \%$ of all runners in 161-km ultra-marathons in North America in 1996 (Hoffman, 2010). The highest increase in participants was reported for athletes aged 40-59 years (men: 5059, women: 40-49) in 161-km ultra-marathons in the 'Western States 100-Mile Endurance Run' (Hoffmann, 2009). Very similar findings were reported for marathon races from the 'New York City Marathon', where the increase was highest in the age groups 30-39 and 40-49 years (men: 40-49, women: 30-39) (Jokl et al., 2004).

Regarding the development of gender differences findings vary quite a bit for different types of competitions. For shorter races such as the marathon distance, the gender difference in participation, indicated by the male-to-female ratio, was greatest at the earliest time investigated and afterwards linearly dropped towards one, as female athletes slowly caught up in participation (Jokl et al., 2004). However, in much longer races such as multi-stage ultra-marathons, the male-to-female ratio showed an opposite development with an increasing gap over the investigated time between male and female athletes (Abou Shoak et al., 2013). 
So far, studies investigating participation and performance trends in endurance running have primarily focused on historical data from one specific event, such as the 'Western States 100-Mile Endurance Run' (Hoffmann et al., 2010) or the 'New York City Marathon' (Jokl et al., 2004). In the present study, however, we aimed to get a more global overview on participation trends. In order to achieve this, we examined data from all races held word-wide since the beginning of the 6-hour ultra-marathon. The aim of this study was to investigate participation trends all in 6-hour ultra- runs held worldwide between 1991 and 2010 and where these races took place with focus on the development of the male-to-female ratio and the age of participants. Furthermore, we intended to examine the influence of nationality on performance based on the top ten performances from each country and continent. Based upon present literature we hypothesized a constant increase in the number of participants. We expected this increase to be highest amongst runners in the age group 40-49 years for both men and women. Overall, it was expected that the increase would be greater amongst women than men. This higher increase in female participants compared to male participants may lead to a decreasing gap between men and women, indicated by a dropping male-tofemale ratio. For the top ten athletes' performance we hypothesized to find a dominance of African runners as described in previous research on shorter competitions.

\section{MATERIAL AND METHODS}

All runners who have ever participated in a 6-hour ultra-marathon held worldwide between 1991 and 2010 were analysed regarding the association between gender, nationality and age with their race performance. The data set from this study was obtained from the website http://www.ultra-marathon.org. This data base collects all race results in ultra-marathon races held worldwide. Data before 1991 seemed incomplete and therefore not reliable for data analysis. The study was approved by the Institutional Review Board of St. Gallen, Switzerland, with waiver of the requirement for informed consent given that the study involved the analysis of publicly available data.

Data from 30,318 athletes was available, including 5,872 women and 24,406 men. The athletes originated from 55 different countries all over the world and had the opportunity to participate in 236 different races held in 35 countries in all continents. In order to analyse participation trends with regard to gender, we considered the number of female and male participants year by year. To determine the development of participants with regard to the country of origin, first the total number of male and female participants per country was established. Following this, the annual development of male and female participants for all countries with at least 500 participants in total was determined and analysed. These countries were Japan, Australia, Germany, France, the Netherlands, Russia, Austria, Italy, Norway, Sweden, Belgium, Czech Republic, Denmark, the United States of America and Canada. Furthermore, we determined every runner's continent of origin and categorised them according to the continent on which their races took place. In this manner, we were able to get an overview on how far away from home athletes started in races. For these tables and figures, the continent of Australia holds data from the countries Australia and New Zealand.

The development of participation in the different age groups in men and women was analysed. The participants were categorised into the age groups 18-24, 25-29, 30-34, 35-39, 40-44, 45-49, 50-54, 55-59, $60-64,65-69,70-74$ and $75-79$ years. Afterwards, the number of male and females athletes per age group was determined and analysed. A total of 2,796 men and 753 women could not be included in the analysis of age groups because no information about age was recorded. 
The development of athletes' participation according to host continent and according to host country was analysed. For all continents, the number of women and men participating in 6-hour ultra-marathons taking place on the respective continent were determined and analysed. In analysing the number of women and men according to the country in which their race took place, we only considered countries that hosted races in more than half of the regarded time frame (i.e. in at least 11 out of 20 years). These countries were Australia, Canada, the Czech Republic, France, Germany, the Netherlands, Russia and the United States of America, respectively.

The overall top ten performances (e.g. ten highest running distances) for men and women according to continent of origin and country of origin were determined. Because there were less than the necessary ten African female participants, African women were excluded from this analysis. Additionally, we investigated only those countries with at least 500 participants in total, which were the countries with the highest number of all athletes. As a final step, we analysed the coherence of development in population, income per head and number of finishers for the above mentioned 15 nations with more than 500 participants in total.

\section{Statistical analysis}

In order to increase the reliability of data analyses, each set of data was tested for normal distribution as well as for homogeneity of variances in advance of statistical analyses. Normal distribution was tested using a D'Agostino and Pearson omnibus normality test and homogeneity of variances was tested using a Levene's test in case of two groups and with a Bartlett's test in case of more than two groups. To find significant changes in the development of a variable across years, linear regression was used. Correlation analyses were performed using Pearson's correlation in case of normal distributed data and Spearman's correlation in case of not normal distributed data. Statistical analyses were performed using IBM SPSS Statistics (Version 19, IBM SPSS, Chicago, IL, USA) and GraphPad Prism (Version 5, GraphPad Software, La Jolla, CA, USA). Significance was accepted at $\mathrm{P}<0.05$ (two-sided for t-tests). Data in the text are given as mean \pm standard deviation (SD).

\section{RESULTS}

\section{Localization of the races}

The five countries that started holding 6-hour ultra-marathons first in the examined time frame were the Netherlands, Russia, Australia, Germany and Canada (Table 1). In 2005 was a sharp increase in 6-hour runs being held in all the investigated countries, except for Kazakhstan, Taiwan and Monaco. Between 1991 and 2010 Europe hosted most of the 6-hour ultra-marathons with 994 races, followed by North America with 134 races. Regarding single countries, France with 169 races, Germany with 135 races and the United States of America with 108 races accounted for the largest part of those competitions.

Table 1. Countries with at least one 6-hour ultra-marathon. JPN=Japan, KAZ=Kazakhstan, TPE=Taipei, AUS $=$ Australia, NZL=New Zeeland, AUT=Austria, BEL=Belgium, BLR=Belarus, CZE=Czech Republic, $D E N=D e n m a r k, E S P=S p a i n, E S T=E s t o n i a, F i n=F i n l a n d, F R A=F r a n c e, G B R=$ Great Britain, GER=Germany, GRE=Greece, Hun=Hungary, ISL=Iceland, ITA=Italy, Mon=Monaco, NED=Netherland, NOR=Norway, $P O L=P o l a n d, R U S=R u s s i a, S L O=S l o v e n i a, S R B=S e r b i a$, Sui=Switzerland, $S V K=S l o v a k i a, S W E=S w e d e n$, UKR=Ukraine, $C A N=$ Canada, USA=United States of America, $A R G=A r g e n t i n a, B R A=B r a z i l$. 


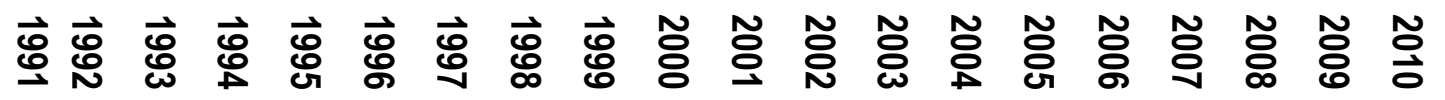

\begin{tabular}{|c|c|c|c|c|c|c|c|c|c|c|c|c|c|c|c|c|c|c|c|}
\hline \multicolumn{20}{|l|}{$\begin{array}{l}\text { JPN } \\
\text { KAZ } \\
\text { TPE }\end{array}$} \\
\hline AUS & 1 & 4 & 1 & & & & 1 & 2 & 1 & 2 & 3 & 5 & 4 & 4 & 6 & 6 & 5 & 7 & 9 \\
\hline NZL & & & & & & & 1 & 1 & 1 & 1 & & & & 1 & 1 & & 1 & 1 & 1 \\
\hline AUT & & & & & & & & & & & & 1 & 4 & 5 & 3 & & & & 6 \\
\hline BEL & & & 1 & & 1 & 1 & 1 & & & & 1 & & & & 1 & & & & 1 \\
\hline BLR & & & & & & & & & & & & & & 1 & 1 & 1 & 1 & 1 & \\
\hline CZE & & & & & & 1 & 1 & & 1 & 1 & & & 1 & 2 & 2 & 2 & 2 & 2 & 2 \\
\hline DEN & & & & & & & & & & & & & & & & 2 & 4 & 5 & 5 \\
\hline ESP & & & & & & & & & & 1 & & 2 & 1 & 1 & 2 & 1 & 2 & 2 & 3 \\
\hline EST & & & & & & & & & & & & & & & 1 & 1 & & & 1 \\
\hline FIN & & & & & & & & & & & & & 1 & 1 & 1 & 1 & 1 & 3 & 2 \\
\hline FRA & & & & & 1 & & & & & 2 & 1 & 2 & 3 & 13 & 17 & 20 & 20 & 22 & 36 \\
\hline GBR & & & & & & & & & & & & & & & 1 & & 2 & 1 & 1 \\
\hline GER & & & & & & & 1 & 2 & 3 & 4 & 5 & 7 & 9 & 9 & 14 & 11 & 13 & 17 & 16 \\
\hline GRE & & & & & & & & & & & & & & & 1 & & & 2 & \\
\hline HUN & & & & & & & & & & & & & & 2 & 2 & 3 & 3 & 2 & 2 \\
\hline ISL & & & & & & & & & & & & & & & 1 & 1 & 1 & & \\
\hline ITA & & & & & & & & & & & & & 5 & 3 & 2 & 3 & 3 & 6 & 9 \\
\hline MON & & & & & & & & & & & & & & & & & & & 1 \\
\hline NED & & 1 & 1 & 1 & 2 & 2 & 2 & 4 & 8 & 7 & 7 & 9 & 7 & 8 & 9 & 7 & 7 & 6 & 6 \\
\hline NOR & & & & & & & & & & & & & & 1 & 1 & 1 & 1 & 2 & 3 \\
\hline POL & & & & & & & & & & & & & & 1 & 1 & & & & \\
\hline RUS & 1 & 1 & 1 & & & 2 & 1 & 1 & 1 & 2 & 2 & 2 & 3 & 4 & 4 & 4 & 4 & 4 & 3 \\
\hline SLO & & & & & & & & & & & & & & & & 1 & 1 & 1 & 1 \\
\hline SRB & & & & & & & & & & & & & & & & & & 1 & 1 \\
\hline SUI & & & & & & & & & & & & & & & & 1 & & & \\
\hline SVK & & & & & & & 1 & 1 & 1 & 1 & & & 1 & 1 & & 1 & 1 & 2 & 1 \\
\hline SWE & & & & & & & & & & & & & & 1 & 2 & 4 & 5 & 7 & 4 \\
\hline UKR & & & & & & & & & & & & & & 1 & & & & & \\
\hline CAN & & & & & 2 & 2 & 2 & 2 & 1 & 2 & 2 & 2 & 2 & 2 & 2 & 3 & 2 & 8 & 9 \\
\hline USA & & & & & & 1 & & & 1 & & 4 & 5 & 5 & 8 & 8 & 7 & 9 & 15 & 20 \\
\hline ARG & 2 & & & & & & & & & & & & & & & 1 & & 1 & 1 \\
\hline BRA & & & & & & & & & & & & & & & & & 2 & & \\
\hline
\end{tabular}

Participation trends

Participation in 6-hour ultra-marathons increased linearly in both men $(r 2=0.85 ; P<0.001)$ and women $(r 2$ $=0.82 ; P<0.001$ ) (Figure 1). Between 1991 and 2010 participation was always higher in men than in women $(P=0.013)$. This difference between female and male participation, as indicated by male-to-female ratio, remained remarkably stable at $\sim 4$ between 1996 and 2010. The year 1994 appeared to be an outlier 
with an uncommonly high number of male participants of over 100 , which then dropped in the next year to 23 again. This outlier also affected the male-to-female ratio, which increased to over 25 this year.

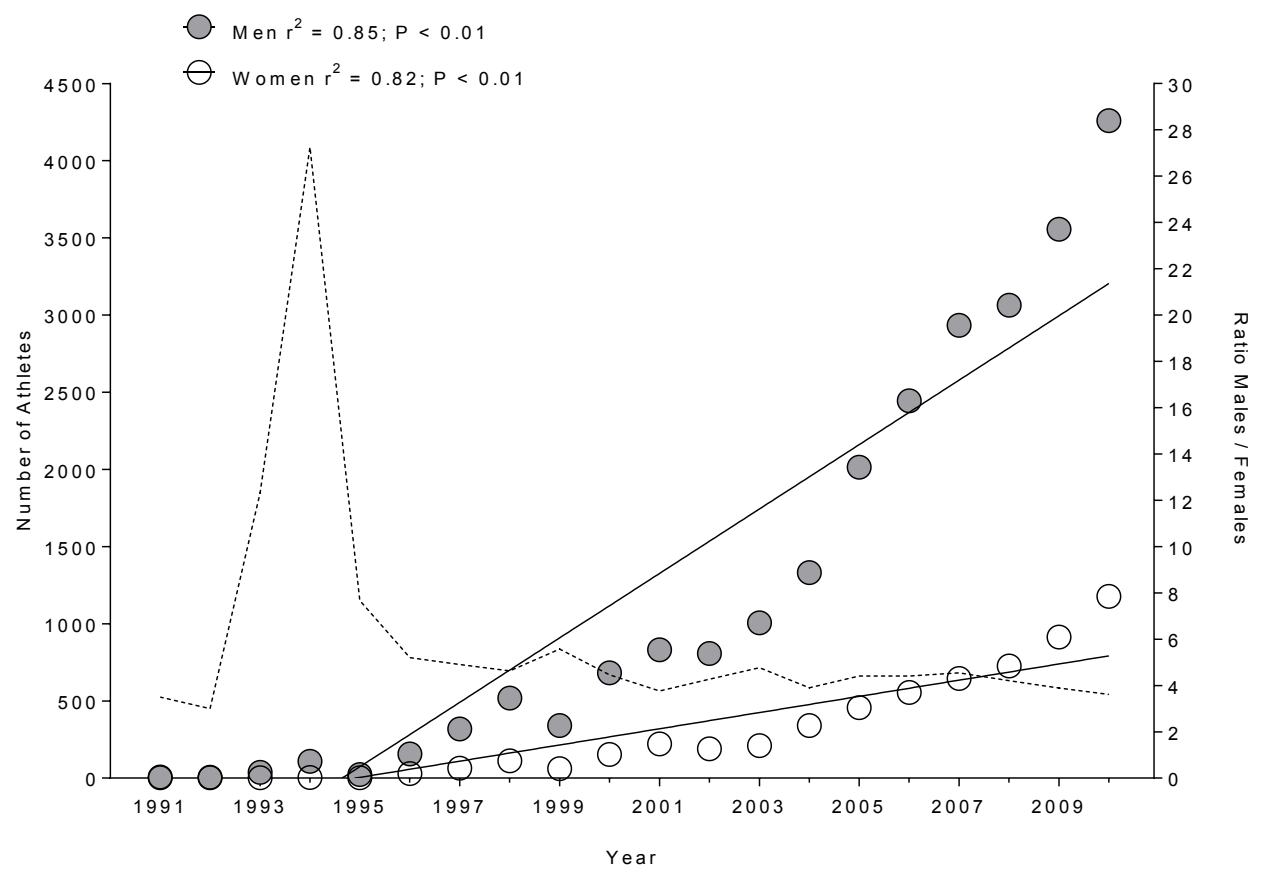

Figure 1. Annual number of male and female participants in all 6-hour ultra runs worldwide. The dotted line shows the male-to-female ratio

There were few countries accounting for the vast majority of 6-hour ultra-marathoners. These were defined at a cut-off at 500 participants and sorted from most to least participants such as Germany, France, the Netherlands, Russia, Austria, Italy, the United States of America, Norway, Sweden, Canada, Belgium, the Czech Republic, Denmark, Australia, and Japan (Figure 2). The number of participants increased in all 15 countries with more than 500 participants in total for men and women (Figure 3). The largest increase in the number of 6-hour ultra-marathoners occurred in Germany and France for both men and women. These two countries alone accounted for $38 \%$ of all participants in Europe. While this development started in Germany in 1994, the upcoming of this kind of competition in France was delayed until its breakthrough two years later in 1996.

Where do 6-hour ultra-marathoners compete?

In addition to where runners came from the question as to where they competed in 6-hour ultra-marathons should also be further examined. Comparing these two aspects delivered information on runners travelling behaviour. Figure 4 shows where runners came from and where they competed separated into the five continents Asia (Panel A), Australia (Panel B), Europe (Panel C), North America (Panel D) and South America (Panel E). For every continent, runners also living in the hosting continent made up the vast majority of participants. Europe stands out as a host-country for 6-hour ultra-marathons because it hosted most of the races and had the most diverse and international field of participants. Europe was the only continent that had participants both men and women from every other continent. South America on the other hand had only participants from South America. Only six male African runners competed in foreign 
continents, two in Australia and four in Europe. There was no significant difference in the percentage of travelling readiness between male and female runners (Table 2).

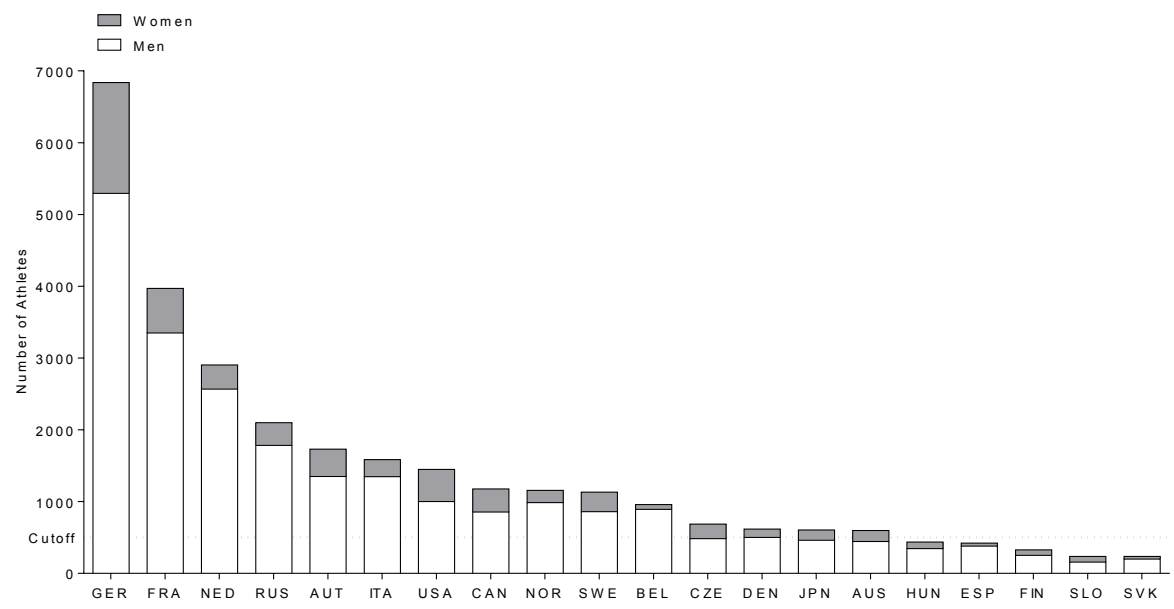

Figure 2. Number of male and female participants per country for the 20 countries with the total (men and women) highest number of finishers. Additionally, the cut-off-line (500 participants total) for the further analysis by year is given. GER= Germany, FRA=France, NED=Netherland, RUS=Russia, AUT=Austria, ITA=Italy, USA=United States of America, CAN=Canada, NOR=Norway, SWE=Sweden, BEL=Belgium, $C Z E=C z e c h$ Republic, DEN=Denmark, JPN=Japan, AUS=Australia, HUN=Hungary, ESP=Spain, FIN=Finland, SLO=Slovenia, SVK=Slovakia

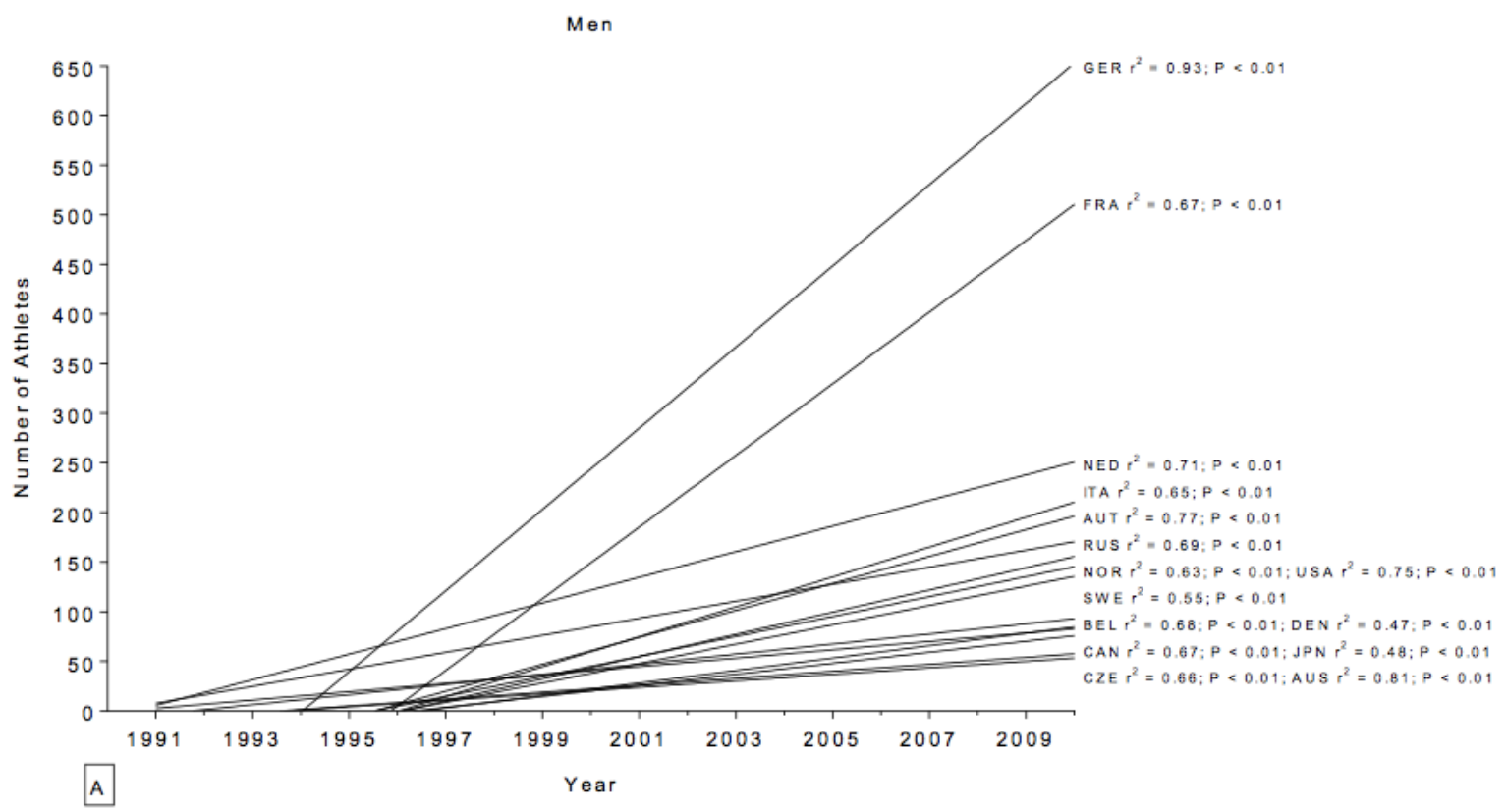




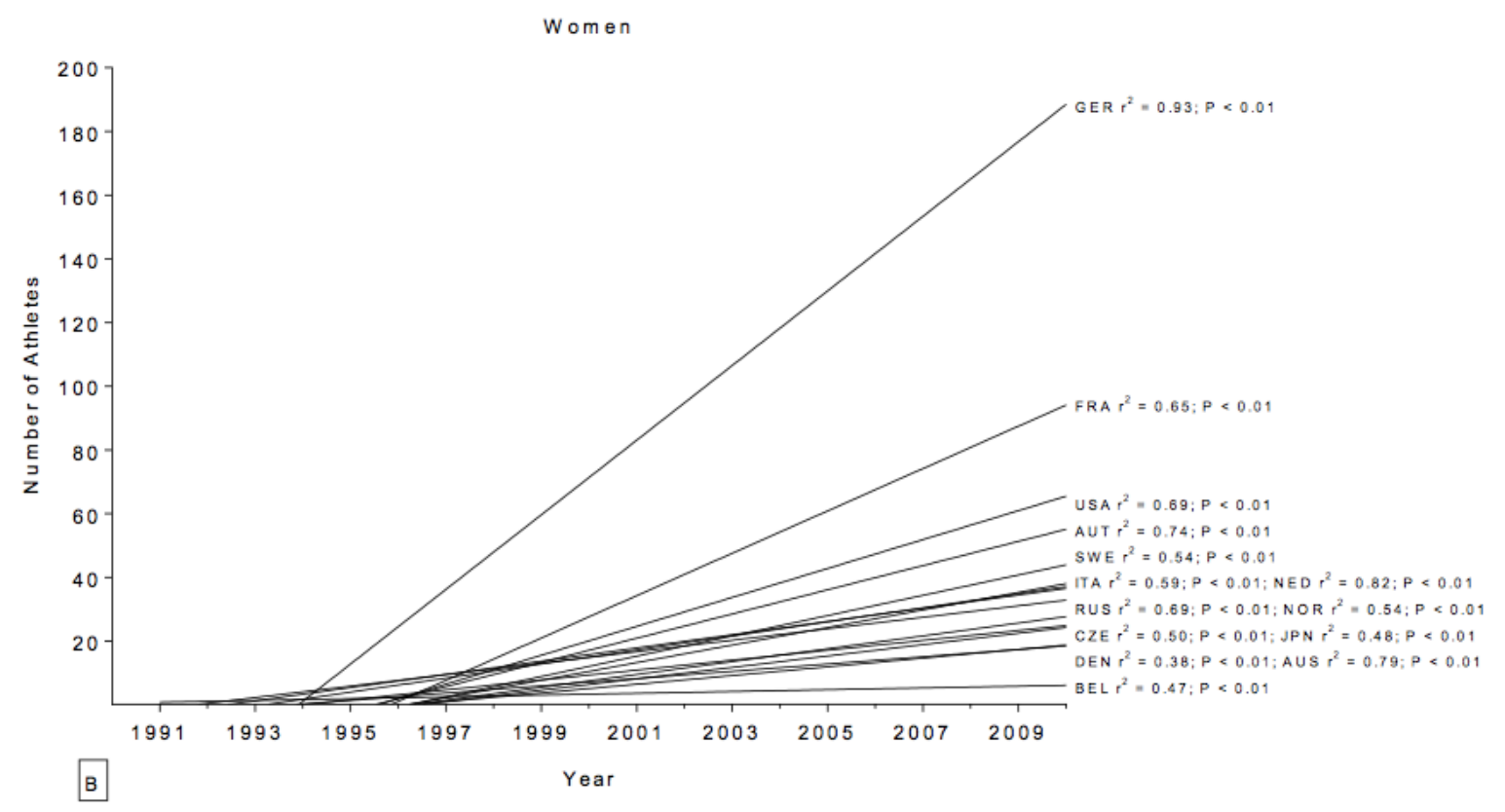

Figure 3. Annual development of participation in nations with more than 500 participants in total for men (Panel A) and women (Panel B). GER= Germany, FRA=France, NED=Netherlands, ITA=Italy,

$A U T=$ Austria, RUS=Russia, NOR=Norway, USA=United States of America, SWE=Sweden, BEL=Belgium, $D E N=$ Denmark, $C A N=$ Canada, JPN=Japan, CZE= Czech Republic, AUS=Australia

Table 2. Where travelling runners come from (left column) and where they travel to (top row) for competition, as well as the percentage amount of athletes travelling for women and men. This difference was not significant $(P=0.1933)$

\begin{tabular}{|c|c|c|c|c|c|c|c|}
\hline & Europe & $\begin{array}{c}\text { North } \\
\text { America }\end{array}$ & Australia & Asia & $\begin{array}{c}\text { South } \\
\text { America }\end{array}$ & Travellers & All \\
\hline Europe Men & $21^{\prime} 431$ & 29 & 5 & 1 & & 35 & $21^{\prime} 466$ \\
\hline Europe Women & $4^{\prime} 743$ & 4 & 1 & 3 & & 8 & $4 ' 751$ \\
\hline North America Men & 41 & $1 ' 813$ & 1 & & & 42 & 1'855 \\
\hline North America Women & 28 & 739 & 2 & & & 30 & 769 \\
\hline Australia Men & 12 & 1 & 462 & 1 & & 14 & 476 \\
\hline Australia Women & 15 & & 163 & & & 15 & 178 \\
\hline Asia Men & 46 & 1 & & 492 & & 47 & 539 \\
\hline Asia Women & 14 & 1 & & 139 & & 15 & 154 \\
\hline South America Men & 4 & & & & 100 & 4 & 104 \\
\hline South America Women & 2 & & & & 18 & 2 & 20 \\
\hline Africa Men & 10 & 1 & 2 & & & 13 & 13 \\
\hline Runners travelled Women (\%) & & & & & & 1.192 & \\
\hline Runners travelled Men (\%) & & & & & & 0.587 & \\
\hline
\end{tabular}



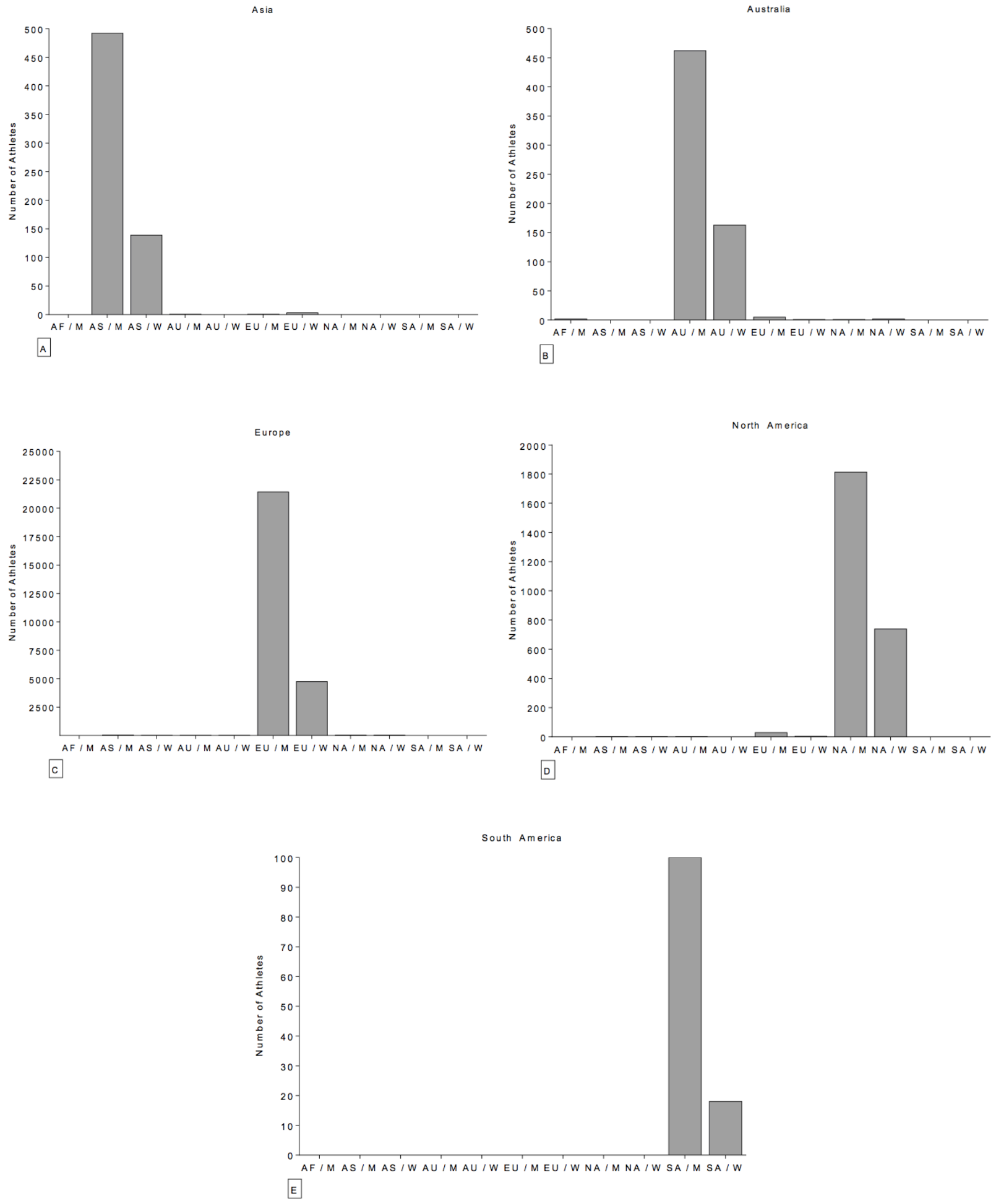

Figure 4. The number of male and female participants per continent in all competitions in Asia (Panel A), Australia (Panel B), Europe (Panel C), North America (Panel D) and South America (Panel E) 


\section{Age of participants}

Figure 5 shows the development of participants in age groups for men (Panel A) and women (Panel B). Athletes in all age groups showed a significant increase in the number of participants for men and women with the only exception of women aged 70-79 years. Runners in the age group 45-49 showed the largest increase over time and the highest overall number for men and women. Younger runners in the age groups 18-24 and 24-29 on the other hand showed a much smaller increase for both men and women.
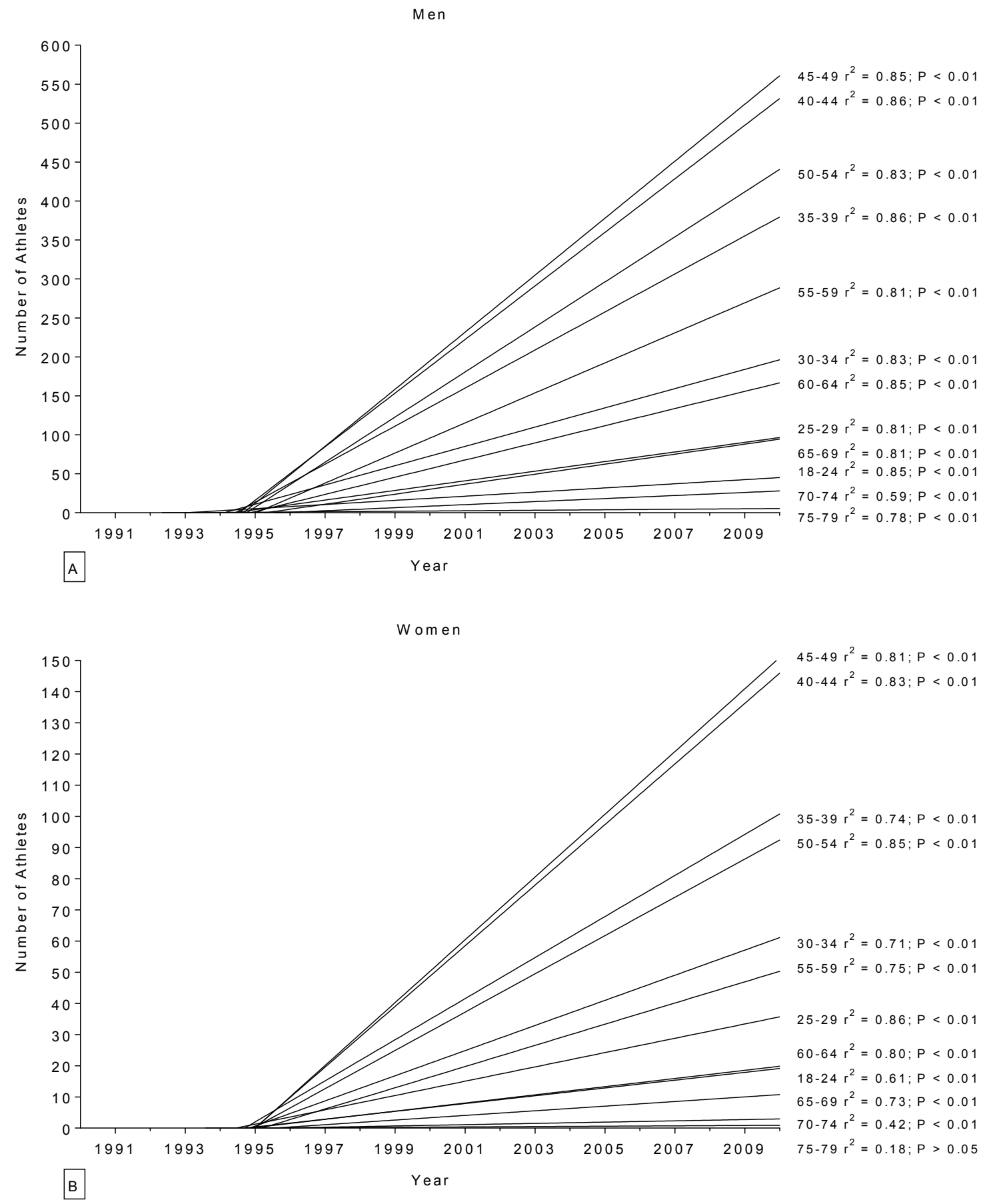

Figure 5. Annual development of participation in age groups for men (Panel A) and women (Panel B) 


\section{Participation trends in continents}

Figure 6 shows the development of participants per continent. Europe showed the largest increase in participants for both men and women. This is followed by North America, Asia, Australia and South Africa for men and women. Races held in Asia started to gain popularity later than all the other continents (1997) but developed a greater increase of participants over time and therefore passed Australia in total numbers in 1999 for men and in 2002 for women.
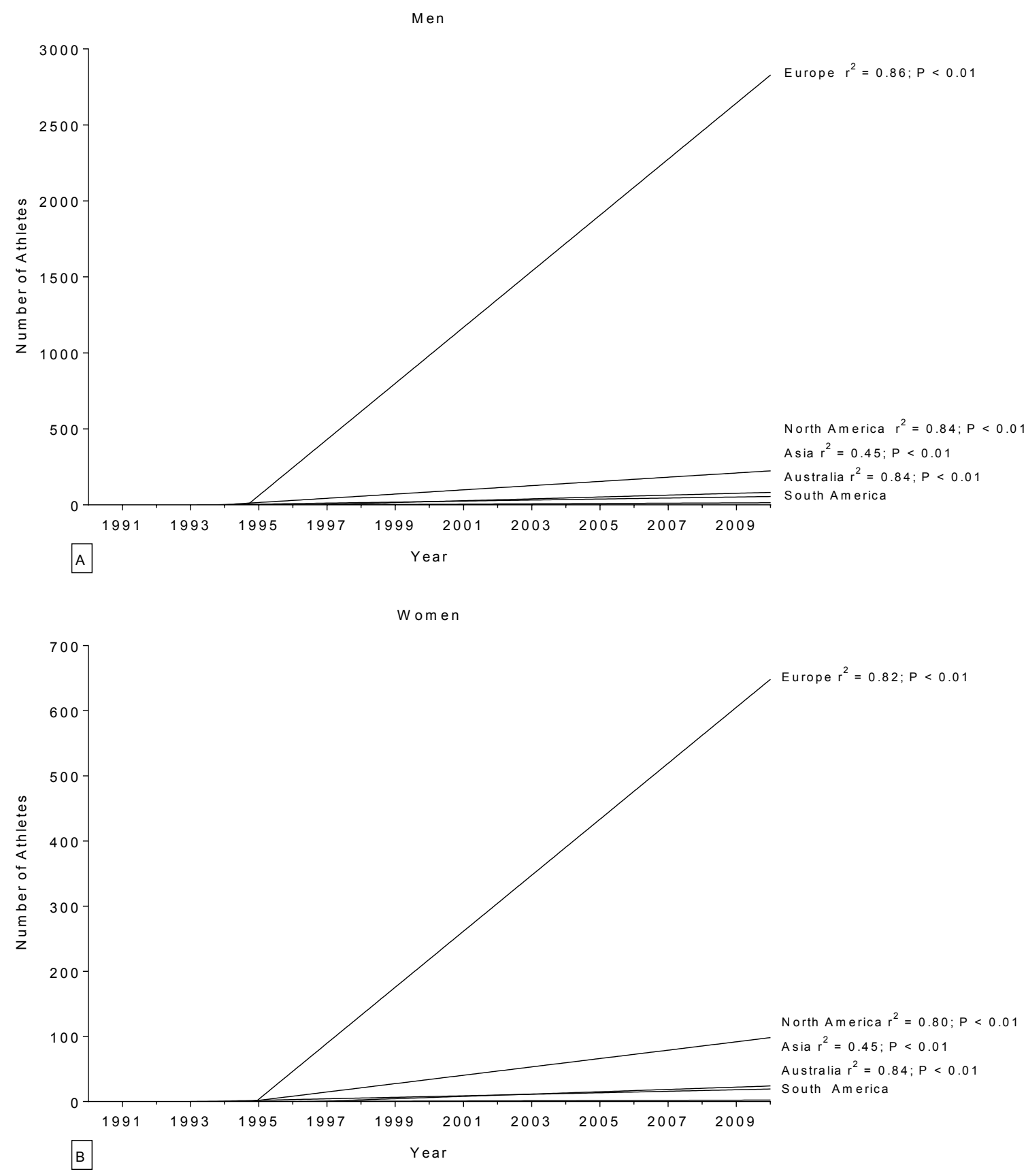

Figure 6. Development of participants per race continent for men (Panel A) and women (Panel B) 


\section{Performance of top ten athletes}

Figure 7 presents the average performance of the top ten athletes per continent of origin for men and women separately. Since there were less than ten female runners from Africa, this continent had been excluded for the female sample. European athletes showed the best top ten performances with $77 \pm 11 \mathrm{~km}$ for men and $73 \pm 3 \mathrm{~km}$ for women. Only slightly weaker were the performances of the top ten athletes from North America (men $=76 \pm 2 \mathrm{~km}$, women $=68 \pm 1 \mathrm{~km}$ ), Australia (men=76 $\pm 2 \mathrm{~km}$, women $=67 \pm 2 \mathrm{~km}$ ) and Asia (men $=74 \pm 3 \mathrm{~km}$, women $=68 \pm 3 \mathrm{~km}$ ). Considerably weaker performances are only seen for the top ten athletes from Africa with $65 \pm 9 \mathrm{~km}$ for men and from South America with $65 \pm 2 \mathrm{~km}$ for men and $54 \pm 4 \mathrm{~km}$ for women. These results should be compared to the total number of runners from each continent, where Europe leads with 21466 men and 4751 women and Africa trailing back with only 13 men in total (Table 2).
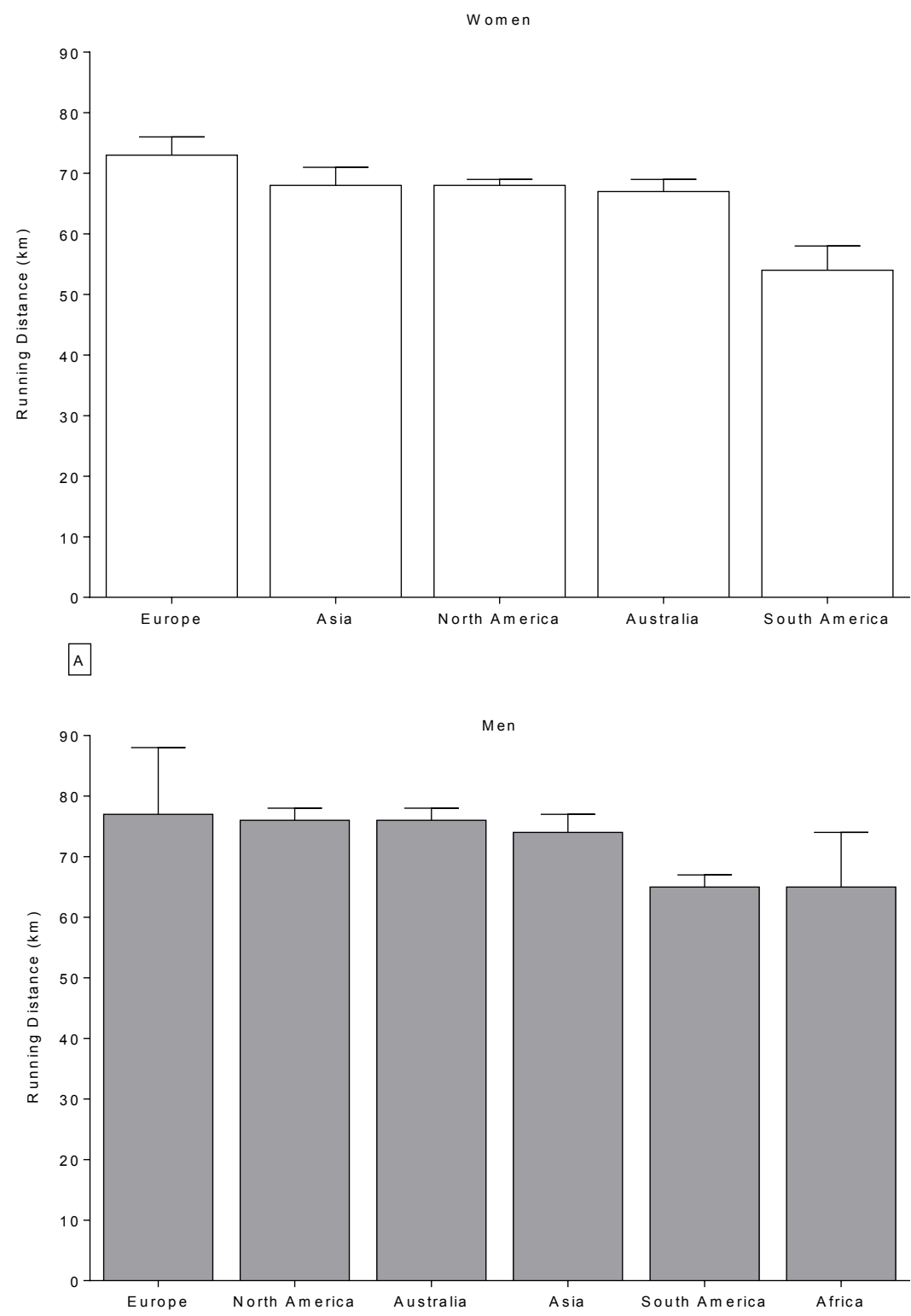

B

Figure 7. Running distance of the overall top ten women (Panel A) and top ten men (Panel B) per continent of origin 
Figure 8 shows the average performance of the top ten athletes per nation of origin for men and women separately, where only the 15 countries with the highest total number of participants were included. The mean running distance for the top ten men ranged from $76 \pm 2 \mathrm{~km}$ (Australia and Canada) up to $89 \pm 1 \mathrm{~km}$ by runners from Russia and for the top ten women from $66 \pm 2 \mathrm{~km}$ by runners from the Czech Republic up to $79 \pm 2 \mathrm{~km}$ by runners from Italy.
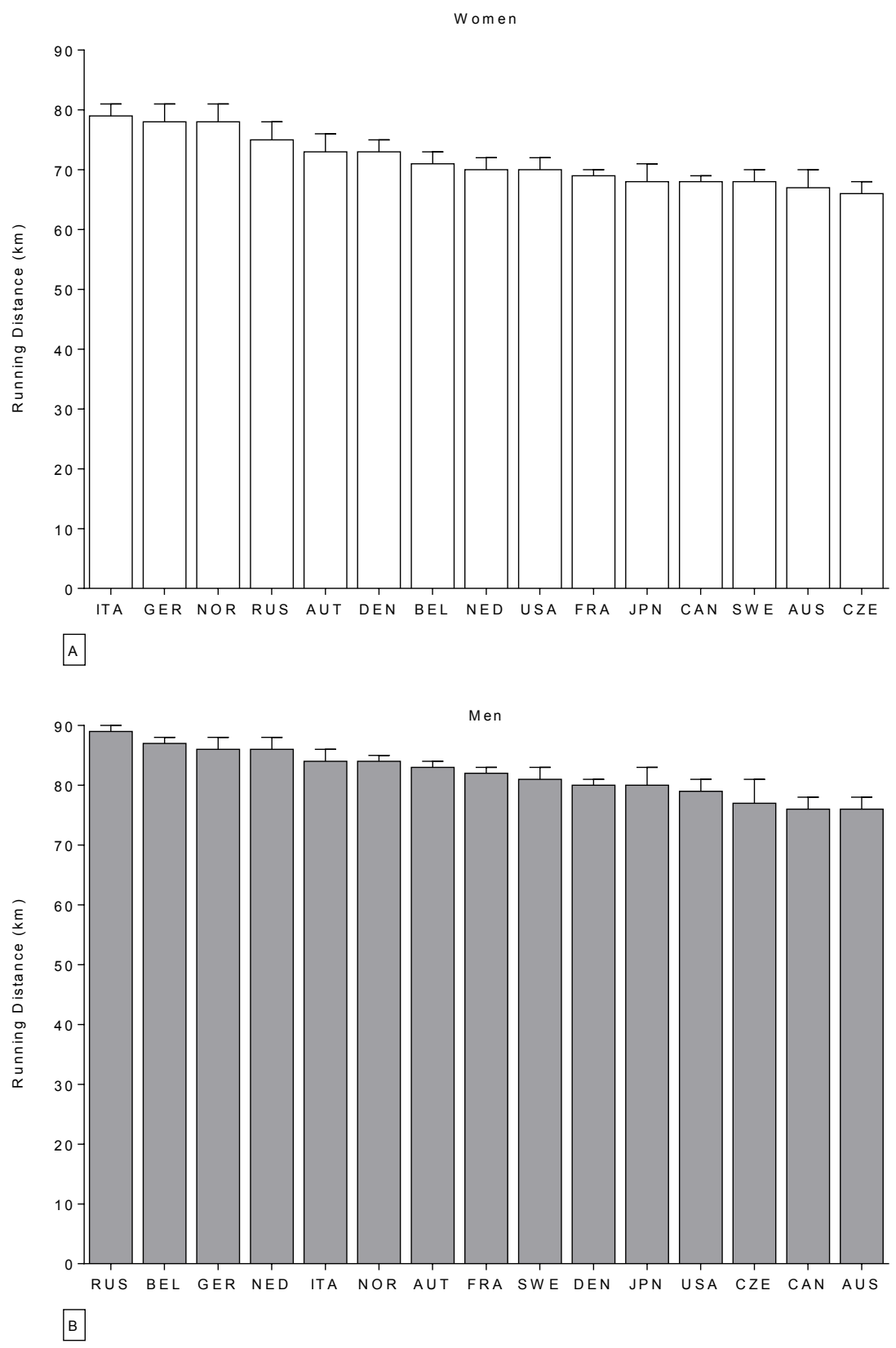

Figure 8. Running distance of the overall top ten female (Panel A) and male (Panel B) athletes per nation of origin. The frame indicates only the 15 countries with the total highest number of participants. GER= Germany, FRA=France, NED=Netherland, RUS=Russia, AUT=Austria, ITA=Italy, USA=United States of

America, $C A N=$ Canada, NOR=Norway, SWE=Sweden, $B E L=$ Belgium, $C Z E=C z e c h$ Republic, $D E N=$ Denmark, JPN=Japan, AUS=Australia, $H U N=$ Hungary, $E S P=S p a i n, F I N=$ Finland, $S L O=S l o v e n i a$, SVK=Slovakia 


\section{DISCUSSION}

The aim of this study was to investigate participation trends in 6-hour ultra-marathons with data from all races held worldwide since 1991. The main findings were (i) a linear increase in the number of participants for both men and women, whereas (ii) most of this development was seen in runners aged $45-49$ years, the (iii) male-to-female ratio remained remarkably stable at around 4, (iv) Europe stands out as a host for 6hour ultra-marathons worldwide by hosting the most races, holding the most diverse field of participants and also providing the most participants in total, and (v) European runners also achieved the best top ten performances, while African and South American runners showed the weakest.

\section{Europe holds the most diverse and international field of participants}

Our first major finding was that races held in Europe showed the most diverse and international field of participants with runners from every other continent for both men and women. Similar findings were reported for multi-stage ultra-marathons (Abou Shoak et al., 2013), Ironman triathlon (Lepers et al., 2011) and Double Iron ultra-triathlon (Sigg et al., 2012). In contrast to Europe, South African races only had runners originating from South Africa. While for every continent local runners accounted for the vast majority of participants, our data still implied that the few runners who were willing to travel to foreign continents to compete, had a high tendency to choose races in Europe. Insights on what motivates ultra endurance runners to compete might be helpful to better understand why Europe is so much more attractive for travelling athletes.

Previous research found that the two strongest motivational factors for female ultra-runners are general health orientation and psychological coping (Krouse et al., 2011), which are both intrinsic motivational factors. Furthermore Ruiz-Juan and Sancho (2012) reported a predominance of intrinsic motivation over external motivation for male and female master athletes to compete in various athletic sports, respectively. Hence we assume the motivation for both male and female 6-hour ultra runners to be mainly of an intrinsic nature as well. Even though intrinsic motivation is predominate for most athletes, motivation remains a very individual issue that varies within runners, so that for some athletes external motivation can still be the main source of motivation. Europe holds some of the largest and therefore most competitive races worldwide such as the 'Troisdorfer 6h-Lauf' in Troisdorf, Germany, the 'de Zes uurs ultraloop Stein' in Stein, the Netherlands or the ' 6 ore dei Templari' in Banzi, Italy (www.ultra-marathon.org), which makes these races particularly attractive for athletes who are mainly driven by external motivation. However, since we have no data on the motivational reasons of specifically travelling athletes, the questions as to why Europe attracts so much more athletes from other continents still remains unexplained.

Germany and France accounted for more than one third of all European participants

Another finding was that races held in Europe showed the highest increase in the total number of runners starting, followed by North America. Within Europe, there were two countries accounting for the vast majority of all runners. Germany and France together accounted for about $38 \%$ of all participants in Europe. This European dominance could also be highlighted by the fact that 11 out of the 15 countries (i.e. Austria, Belgium, the Czech Republic, Denmark, France, Germany, Italy, the Netherlands, Norway, Russia, Sweden, Australia, Canada, the United States of America, and Japan) with the highest number in participants were in Europe. These findings are very similar to previous research on participation trends in ultra-endurance competitions as the Double Iron ultra-triathlon, where $80.9 \%$ of all finishers originated from Europe, Germany and France being also prominent accounting for the most participants within Europe (Sigg et al., 2012). This European dominance was shown for multi-stage ultra-marathon participation as well, with French athletes accounting for most of the participants (Abou Shoak et al., 2013). Since the vast 
majority of participants originate from the host country, it seems plausible that a country's participation could be affected by its population growth.

Therefore we analysed the relation between population and the number of participants for each country and year. Significant and positive correlations were found for all countries except for Russia, due to its shrinking population since 1991. For most countries the number of participants and its population showed a linear increase in the analysed time frame and therefore correlated significantly. While France had one of the highest correlation coefficients (Table 3), Germany had one of the lowest, indicating that there need to be additional factors explaining the high increase of participants compared with France. Another influencing factor could be income, since higher income has the potential to result in more time for idle activities including the time consuming training required for a 6-hour ultra-marathon. Therefore, we also checked for correlation between the income per capita and participation for each country. A significant and positive correlation for income per capita and participants was found for almost all countries, again with the exception of Russia. This showed that in Russia 6-hour ultra-marathons gained popularity and participants even though their population and income did not increase similarly since 1991.

The largest increase in participants took place in the age group 45-49 years

Our second major finding was that the age group 45-49 years showed the largest increase over time and also the highest total number of participants in 6-hour ultra-marathons held between 1991 and 2011 for men and women, respectively. This can be compared to similar findings in 161-km ultra-marathons, where Hoffman et al. (2010) found an increase of runners over 40 years old accounting for less than $40 \%$ in the mid-1980s up to $65-70 \%$ since 1996 of all finishers. However, unlike our findings, they found the highest increase of participants for men above 50 years old compared to the 40-49 years old age group in our findings (Hoffman et al., 2010, Hoffman \& Wegelin, 2009). Similar age groups (men: 40-49 years and women 30-39 years) also showed the largest increase of participants in marathon races (Jokl et al., 2004). The question remains, whether this finding is a consequence of an increasing fitness in these older age groups (Lee \& Tanaka, 1997, Lepers \& Cattagni, 2012) or just a consequence of social changes like awareness and popularity among older age groups (Knechtle et al., 2012, Jokl et al., 2004).

The male-to-female ratio remained remarkably stable

Another major finding was a significant linear increase in participants between 1991 and 2011 for both men and women and a remarkably stable male-to-female ratio since 1996. This constant gain in popularity has been described in other ultra-endurance competitions such as 100-km ultra-marathon (Knechtle et al., 2012), 161-km ultra-marathon (Hoffman et al., 2010) and multi-stage ultra-marathon (Abou Shoak et al., 2013). We hypothesized that the male-to-female ratio would show a linear drop towards one, as described in previous literature in marathoners (Jokl et al., 2004) and 161-km ultra-marathoners (Hoffman et al., 2010). Although there is a tendency to a decrease in the male-to-female ratio, it is barely noticeable and smaller than hypothesized. A possible explanation for this deviation from previous findings could be that 6hour ultra running is a rather young discipline, which has only been popular since 1993, while previous research was done for older sports, with a history of male dominance in participation (Jokl et al., 2004) In 6hour ultra-marathons such a historical male dominance has never been comparably established and can therefore not be softened equally. 
Table 3. Top 15 countries with the most overall participants (left row). Participants, population and income per person in 1991 and 2010 with r2 and $P$-values. Participants compared with population and income with Pearson correlation coefficients $r$ and $P$-values. $n s=n o n$ significant, ukn $=$ unknown. AUT=Austria, BEL=Belgium, CZE=Czech Republic, DEN=Denmark, FRA=France, GER=Germany, NED=Netherland, NOR=Norway, RUS=Russia, SWE=Sweden, AUS=Australia, CAN=Canada, USA=United States of America, ITA=Italy, JPN=Japa

\begin{tabular}{|c|c|c|c|c|c|c|c|c|c|c|c|c|c|c|c|c|}
\hline & \multicolumn{4}{|c|}{ Participants } & \multicolumn{4}{|c|}{ Population (in 1'000) } & \multicolumn{4}{|c|}{ Income per Person (in 1'000) } & \multicolumn{2}{|c|}{$\begin{array}{l}\text { Participants/ } \\
\text { Population }\end{array}$} & \multicolumn{2}{|c|}{$\begin{array}{l}\text { Participants/ } \\
\text { Income }\end{array}$} \\
\hline & 1991 & 2010 & $r^{2}$ & $P$ & 1991 & 2010 & $r^{2}$ & $P$ & 1991 & 2010 & $r^{2}$ & $P$ & $r$ & $P$ & $r$ & $P$ \\
\hline AUT & 0 & 103 & 0.65 & $<0.01$ & 7,720 & 8,419 & 0.98 & $<0.01$ & 20,320 & 41,970 & 0.98 & $<0.01$ & 0.84 & $<0.01$ & 0.84 & $<0.01$ \\
\hline BEL & 0 & 0 & 0.01 & ns & 9,976 & 10,951 & 0.91 & $<0.01$ & 19,700 & 39,300 & 0.99 & $<0.01$ & -0.03 & ns & -0.03 & Ns \\
\hline CZE & 0 & 28 & 0.53 & $<0.01$ & 10,307 & 10,546 & 0.15 & ns & ukn & 24,190 & 0.95 & $<0.01$ & 0.41 & ns & 0.75 & $<0.01$ \\
\hline DEN & 0 & 365 & 0.44 & $<0.01$ & 5,155 & 5,574 & 1 & ns & 18,820 & 42,330 & 0.99 & ns & 0.75 & $<0.01$ & 0.75 & $<0.01$ \\
\hline FRA & 0 & 1,091 & 0.65 & $<0.01$ & 58,455 & 65,437 & 0.99 & ns & 17,880 & 35,860 & 0.99 & ns & 0.92 & $<0.01$ & 0.92 & $<0.01$ \\
\hline GER & 0 & 893 & 0.92 & ns & 7,9652 & 81,726 & 0.43 & $<0.01$ & 20,140 & 40,170 & 0.95 & ns & 0.63 & $<0.01$ & 0.98 & $<0.01$ \\
\hline NED & 0 & 296 & 0.70 & ns & 14,995 & 16,696 & 0.99 & ns & 18,510 & 43,770 & 0.98 & ns & 0.77 & $<0.01$ & 0.78 & $<0.01$ \\
\hline NOR & 0 & 265 & 0.68 & ns & 4,263 & 4,952 & 0.97 & ns & 18,410 & 58,090 & 0.96 & ns & 0.89 & $<0.01$ & 0.82 & $<0.01$ \\
\hline RUS & 2 & 42 & 0.44 & ns & 148,674 & 141,930 & 0.96 & $<0.01$ & 7,830 & 20,050 & 0.76 & ns & -0.67 & $<0.01$ & 0.55 & $>0.01$ \\
\hline SWE & 0 & 213 & 0.56 & ns & 8,617 & 9,453 & 0.90 & ns & 19,270 & 42,350 & 0.97 & ns & 0.82 & $<0.01$ & 0.81 & $<0.01$ \\
\hline AUS & 0 & 121 & 0.84 & ns & 17,321 & 22,621 & 0.98 & ns & 17,030 & 40,234 & 0.99 & ns & 0.95 & $<0.01$ & 0.93 & $<0.01$ \\
\hline CAN & 0 & 161 & 0.77 & ns & 28,052 & 34,483 & 1 & ns & 18,850 & 39,730 & 0.98 & ns & 0.88 & $<0.01$ & 0.83 & $<0.01$ \\
\hline USA & 0 & 423 & 0.73 & $<0,01$ & 255,808 & 311,592 & 1 & ns & 23,300 & 48,890 & 0.98 & ns & 0.93 & $<0.01$ & 0.92 & $<0.01$ \\
\hline ITA & 0 & 538 & 0.66 & $<0.01$ & 56,856 & 60,770 & 0.83 & ns & 18,180 & 32,350 & 0.97 & ns & 0.87 & $<0.01$ & 0.86 & $<0.01$ \\
\hline JPN & 0 & 349 & 0.49 & $<0.01$ & 122,703 & 127,817 & 0.90 & ns & 20,630 & 35,510 & 0.97 & ns & 0.78 & $<0.01$ & 0.88 & $<0.01$ \\
\hline
\end{tabular}


A small but constant decrease can be found since 2007, which could also highlight a somewhat delayed development towards a smaller male-to-female ratio in 6-hour ultra-marathons. This suggests a hypothesis that brand new endurance competitions first attract mostly male runners, while female runners slowly take over already established competitions such as the ultra-triathlon or the marathon. However, to verify this hypothesis further tracing of the male-to-female ratio over an extended time period, especially in the next years, is needed.

\section{European runners achieved the best top ten performances}

Only very little differences were seen for the top ten performances by runners from Europe, Asia, North America and Australia, with only runners from Africa being noticeably weaker for men and women, respectively. Athletes originating from continents with a larger number of runners participating in these 6hour ultra-marathons have a statistically higher chance of also achieving better top ten performances. Hence to better interpret the mentioned top ten performances they should be put in relation to the total amount of runners from each continent. With this in mind, the rather weak top ten performances by African runners can be explained by the fact that there are only 13 African runners in total. European runners, who achieved the best top ten performances for both men and women, also had the highest total number of runners (Table 2), which can help explaining its number one position in this ranking.

Nevertheless the weak top ten performances by African runners was surprising since African runners dominated other middle- and long-distance running competitions for years (Onywera et al., 2006). For example, Kenyan runners alone accounted for more than $50 \%$ of the all-time top 20 performances in middle- and long-distance races from $800 \mathrm{~m}$ to the marathon in 2003 (Larsen, 2003). Several studies tried to find possible explanations for this unique success of East African runners, including advantageous environmental conditions (Onywera et al., 2006), a better running economy (Saltin et al., 1995), a psychological advantage (Baker \& Horton, 2003) and the ability to maintain at a higher \%VO2max at distances over $5 \mathrm{~km}$ (Coetzer et al., 1993).

However, the dominance of African runners has been shown for races not exceeding the distance of the marathon (Knechtle et al., 2013, Eichenberger et al., 2013), therefore not including the longer 6-hour ultramarathons. The average distance run by the top 10 athletes was approximately $72 \mathrm{~km}$ for men and approximately $66 \mathrm{~km}$ for women. Compared with the $42 \mathrm{~km}$ distance of a marathon this makes a difference in performed distance of about $70 \%$, which can help explain the gap in the performance and why the described advantages of East African runners seem to not apply for 6-hour ultra-marathons. However, it's more likely that the weak top ten performances of African runners is due to the very small number of only 13 athletes in total. Therefore these unexpected results should be interpreted with caution and the question remains as to why the discussed advantages of African runners should vanish this abruptly with longer running distances over $42 \mathrm{~km}$ since at least the better running economy and psychological advantage should remain, regardless of the running distance.

Furthermore it seems questionable, if the ability to remain at a higher \%VO2max over time of Kenyan runners decreases, or that this is not as important anymore with longer running distances. There could be other factors gaining importance with longer running distances and thereby overcoming the discussed unique physiological and psychological skills of African runners. However further data and further investigation is needed to better understand how the discussed advantages of East African runners may or may not transfer to competitions exceeding the distance of the marathon. 


\section{Limitations}

This study has some limitations, including a lack of more detailed knowledge on motivational factors for specifically 6-hour ultra-marathoners, to be able to better interpret our findings on participation trends. Furthermore performance influencing factors, such as anthropometric characteristics (Knechtle et al., 2010a, 2010b, 2011), training (Knechtle et al., 2010a, 2010b, 2011), pre-race experience (Knechtle et al., 2010a, 2010b, 2011), V02max (Millet et al., 2011) as well as environmental factors such as temperature (Parise \& Hofman, 2011), were not included in our data. Furthermore more African runners are needed to ensure a less biased analysis on their performance compared to Europeans runners.

\section{CONCLUSION}

To summarize participation trends in world-wide 6-hour ultra-marathons, an overall increase in popularity was found for both men and women. The largest part of this development took place in Europe, especially in Germany and France and was correlated to population growth and income per capita. Europe had the most diverse field of athletes with runners from all other continents. The best top ten performances were seen in Europe, the weakest in Africa and South America, while Europe had most of the runners and Africa with 13 runners the fewest athletes in total. However, to better understand participation trends in 6-hour ultra-marathons, additional data such as motivational reasons, personal expectations and goals for the competition, physical and psychical fitness, training volume and training style as well as number of previous starts in similar ultra-endurance competitions is needed.

\section{REFERENCES}

1. Abou Shoak, M., Knechtle, B., Rüst, C.A., Lepers, R. \& Rosemann, T. (2013). European dominance in multistage ultramarathons: an analysis of finisher rate and performance trends from 1992 to 2010. Open Access J Sports Med, 4, pp.9-18

2. Baker, J. \& Horton, S. (2003). East African running dominance revisited: a role for stereotype threat? Br J Sports Med, 37(6), pp.553-5

3. Coetzer, P., Noakes, T.D., Sanders, B., Lambert, M.I., Bosch, A.N., Wiggins, T. \& Dennis, S.C. (1993). Superior fatigue resistance of elite black South African distance runners. J Appl Physiol, 75(4), pp.1822-7

4. DUV: Deutsche Ultramarathon-Vereinigung. (2013). Retrieved in December 2010, from http://www.ultra-marathon.org.

5. Eichenberger, E., Knechtle, B., Rüst, C.A., Lepers, R., Rosemann, T. \& Onywera, V.O. (2013). The aspect of nationality and performance in a mountain ultra-marathon - the 'Swiss Alpine Marathon'. J Hum Sport Exerc, 7, pp.748-62

6. Herbst, L., Knechtle, B., Lopez, C.L., Andonie, J.L., Fraire, O.S., Kohler, G., Rüst, C.A. \& Rosemann, T. (2011). Pacing strategy and change in body composition during a Deca Iron Triathlon. Chin J Physiol, 54(4), pp.255-63

7. Hoffman, M.D. (2010). Performance trends in 161-km ultramarathons. Int J Sports Med, 31(1), pp.31-7

8. Hoffman, M.D. \& Wegelin, J.A. (2009). The Western States 100-Mile Endurance Run: participation and performance trends. Med Sci Sports Exerc, 41(12), pp.2191-8

9. Jokl, P., Sethi, P.M. \& Cooper, A.J. (2004). Master's performance in the New York City Marathon 1983-1999. Br J Sports Med, 38(4), pp.408-12

10. Knechtle, B., Knechtle, P. \& Lepers, R. (2011a). Participation and performance trends in ultra triathlon from 1985 to 2009. Scand J Med Sci Sports, 21(6), e82-90 
11. Knechtle, B., Knechtle, P. \& Rosemann, T. (2010a). Race performance in male mountain ultramarathoners: anthropometry or training? Percept Mot Skills, 110(3 pt.1), pp.721-35

12. Knechtle, B., Knechtle, P., Rosemann, T. \& Lepers, R. (2010b). Predictor variables for a 100-km race time in male ultra-marathoners. Percept Mot Skills, 111(3), pp.681-93

13. Knechtle, B., Knechtle, P., Rosemann, T. \& Senn, O. (2011b). Personal best time and training volume, not anthropometry, is related to race performance in the 'Swiss Bike Masters' mountain bike ultramarathon. J Strength Cond Res, 25(5), pp.1312-7

14. Knechtle, B., Rüst, C.A., Rosemann, T. \& Lepers, R. (2012). Age-related changes in 100-km ultramarathon running performance. Age (Dordr), 34(4), pp.1033-45

15. Knechtle, B., Rüst, C.A. \& Rosemann, T. (2013). The aspect of nationality in participation and performance in ultra-marathon running - a comparison between 'Badwater' and 'Spartathlon'. OA Sports Medicine, 1(1), p.1

16. Krouse, R.Z., Ransdell, L.B., Lucas, S.M. \& Pritchard, M.E. (2011). Motivation, goal orientation, coaching, and training habits of women ultrarunners. J Strength Cond Res, 25(10), pp.2835-42

17. Larsen, H.B. (2003). Kenyan dominance in distance running. Comp Biochem Physiol A Mol Integr Physiol, 136(1), pp.161-70

18. Lazzer, S., Salvadego, D., Rejc, E., Buglione, A., Antonutto, G. \& Di Prampero, P.E. (2011). The energetics of ultra-endurance running. Eur J Appl Physiol, 112(5), pp.1709-15

19. Lee, M.S. \& Tanaka, K. (1997). Significance of health fitness appraisal in an aging society. Appl Human Sci, 16(4), pp.123-31

20. Lepers, R. \& Cattagni, T. (2012). Do older athletes reach limits in their performance during marathon running? Age (Dordr), 34(3), pp.773-81

21. Lepers, R., Knechtle, B., Knechtle, P. \& Rosemann, T. (2011). Analysis of ultra-triathlon performances. Open Access J Sports Med, 2, pp.131-136

22. Lepers, R. \& Maffiuletti, N.A. (2011). Age and gender interactions in ultraendurance performance: insight from the triathlon. Med Sci Sports Exerc, 43(1), pp.134-9

23. Lucia, A., Esteve-Lanao, J., Oliván, J., Gómez-Gallego, F., San Juan, A.F., Santiago, C., Pérez, M., Chamorro-Viña, C. \& Foster, C. (2006). Physiological characteristic of the best Eritrean runners-exceptional running economy. Appl Physiol Nutr Metab, 31(5), pp.530-40

24. Millet, G.Y., Banfi, J.C., Kerherve, H., Morin, J.B., Vincent, L., Estrade, C., Geyssant, A., \& Feasson, L. (2011). Physiological and biological factors associated with a $24 \mathrm{~h}$ treadmill ultramarathon performance. Scand J Med Sci Sports, 21(1), pp.54-61

25. Onywera, V.O., Scott, R.A., Boit, M.K. \& Pitsiladis, Y.P. (2006). Demographic characteristics of elite Kenyan endurance runners. J Sports Sci, 24(4), pp.415-22

26. Parise, C.A. \& Hoffman, M.D. (2011). Influence of temperature and performance level on pacing a $161 \mathrm{~km}$ trail ultramarathon. Int J Sports Physiol Perform, 6(2), pp.243-51

27. Parry, D., Chinnasamy, C., Papadopoulou, E., Noakes, T., \& Micklereight, D. (2011). Cognition and performance: anxiety, mood and perceived exertion among Ironman triathletes. $\mathrm{Br} J$ Sports Med, 45(14), pp.1088-94

28. Rapoport, B.I. (2010). Metabolic factors limiting performance in marathon runners. PLoS Comput Biol, 6(10), pp.e1000960

29. Ruiz-Juan, F. \& Sancho, A.Z. (2012). Predictor variable of motivation on Spanish master athletes. J Hum Sport Exerc, 7(3), pp.617-28

30. Saltin, B., Larsem, H., Terrados, N., Bangsbo, J., Bak, T., Kim, C.K., Svedenhag, J. \& Rolf, C.J. (1995). Aerobic exercise capacity at sea level and at altitude in Kenyan boys, junior and senior runners compared with Scandinavian runners. Scand J Med Sci Sports, 5(4), pp.209-21 
31. Scott, R.A., Georgiades, E., Wilson, R.H., Goodwin, W.H., Wolde, B. \& Pitsiladis, Y.P. (2003). Demographic characteristics of elite Ethiopian endurance runners. Med Sci Sports Exerc, 35(10), pp.1727-32

32. Sigg, K., Knechtle, B., Rüst, C.A., Lepers, R. \& Rosemann, T. (2012). Central European triathletes dominate Double Iron ultratriathlon - analysis of participation and performance 1985 - 2011. Open Access J Sports Med, 3, pp.159-68

33. Wikimedia Foundation, Inc. (2012). List of countries by life expectancy. Retrieved from http://en.wikipedia.org/wiki/List_of_countries_by_life_expectancy.

34. Zaryski, C. \& Smith, D.J. (2005). Training principles and issues for ultra-endurance athletes. Curr Sports Med Rep, 4(3), pp.165-70 